\title{
Increased attention but more efficient disengagement: Neuroscientific evidence for defensive processing of threatening health information
}

Citation for published version (APA):

Kessels, L. T. E., Ruiter, R. A. C., \& Jansma-Schmitt, B. M. (2010). Increased attention but more efficient disengagement: Neuroscientific evidence for defensive processing of threatening health information. Health Psychology, 29(4), 346-354. https://doi.org/10.1037/a0019372

Document status and date:

Published: 01/01/2010

DOI:

10.1037/a0019372

Document Version:

Publisher's PDF, also known as Version of record

\section{Document license:}

Taverne

Please check the document version of this publication:

- A submitted manuscript is the version of the article upon submission and before peer-review. There can be important differences between the submitted version and the official published version of record.

People interested in the research are advised to contact the author for the final version of the publication, or visit the DOI to the publisher's website.

- The final author version and the galley proof are versions of the publication after peer review.

- The final published version features the final layout of the paper including the volume, issue and page numbers.

Link to publication

\footnotetext{
General rights rights.

- You may freely distribute the URL identifying the publication in the public portal. please follow below link for the End User Agreement:

www.umlib.nl/taverne-license

Take down policy

If you believe that this document breaches copyright please contact us at:

repository@maastrichtuniversity.nl

providing details and we will investigate your claim.
}

Copyright and moral rights for the publications made accessible in the public portal are retained by the authors and/or other copyright owners and it is a condition of accessing publications that users recognise and abide by the legal requirements associated with these

- Users may download and print one copy of any publication from the public portal for the purpose of private study or research.

- You may not further distribute the material or use it for any profit-making activity or commercial gain

If the publication is distributed under the terms of Article 25fa of the Dutch Copyright Act, indicated by the "Taverne" license above, 
See discussions, stats, and author profiles for this publication at: https://www.researchgate.net/publication/45364458

\section{Increased Attention but More Efficient Disengagement: Neuroscientific Evidence for Defensive Processing of Threatening Health Information}

Article in Health Psychology · July 2010

DOI: 10.1037/a0019372 . Source: PubMed

CITATIONS

111

3 authors:

Loes Kessels

Maastricht University

13 PUBLICATIONS 734 CITATIONS

SEE PROFILE

Bernadette M Jansma

Maastricht University

73 PUBLICATIONS 1,869 CITATIONS

SEE PROFILE

Some of the authors of this publication are also working on these related projects:

Project Cognitive Neuroscience of Speech production View project

MERIM study View project
READS

646

Robert A C Ruiter

Maastricht University

298 PUBLICATIONS 9,323 CITATIONS

SEE PROFILE 


\title{
Increased Attention but More Efficient Disengagement: Neuroscientific Evidence for Defensive Processing of Threatening Health Information
}

\author{
Loes T. E. Kessels, Robert A. C. Ruiter, and Bernadette M. Jansma \\ Maastricht University
}

\begin{abstract}
Objective: Previous studies indicate that people respond defensively to threatening health information, especially when the information challenges self-relevant goals. The authors investigated whether reduced acceptance of self-relevant health risk information is already visible in early attention processes, that is, attention disengagement processes. Design: In a randomized, controlled trial with 29 smoking and nonsmoking students, a variant of Posner's cueing task was used in combination with the high-temporal resolution method of event-related brain potentials (ERPs). Main Outcome Measures: Reaction times and P300 ERP. Results: Smokers showed lower P300 amplitudes in response to high- as opposed to low-threat invalid trials when moving their attention to a target in the opposite visual field, indicating more efficient attention disengagement processes. Furthermore, both smokers and nonsmokers showed increased P300 amplitudes in response to the presentation of high- as opposed to low-threat valid trials, indicating threat-induced attention-capturing processes. Reaction time measures did not support the ERP data, indicating that the ERP measure can be extremely informative to measure low-level attention biases in health communication. Conclusion: The findings provide the first neuroscientific support for the hypothesis that threatening health information causes more efficient disengagement among those for whom the health threat is self-relevant.
\end{abstract}

Keywords: attention, threat, ERP, fear appeals, disengagement

Presenting threatening health information by highlighting the negative consequences of unhealthy behavior is often used to motivate people into behaving more healthily. A recent example of this practice is the worldwide introduction of graphic warning labels on cigarette packages, following recommendations of the World Health Organisation's Framework Convention on Tobacco Control and-for member states of the European UnionDirective 2003/641/EC of the European Committee (see also Harris, Mayle, Mabbott, \& Napper, 2007; Ruiter \& Kok, 2005, 2006). Indeed, explanatory models of health behavior suggest that increased risk perception is an important determinant of people's motivation to adopt safer and healthier behavioral alternatives (Fishbein, Triandis, Kanfer, Becker, \& Middlestadt, 2000; Leventhal, 1970; Maddux \& Rogers, 1983; Witte, 1992).

However, a large body of experimental research suggests that people who are at risk report the least motivation to change and subsequently react defensively to threatening health information (e.g., Brown \& Locker, 2009; Croyle, Sun, \& Hart, 1997; Ditto \& Croyle, 2003; Freeman, Hennessy, \& Marzullo, 2001; Keller, 1999; Keller \& Block, 1999; Liberman \& Chaiken, 1992). Early empirical support for counterproductive effects of health messages was found by Liberman and Chaiken (1992). They demonstrated

Loes T. E. Kessels and Robert A. C. Ruiter, Department of Work and Social Psychology, Maastricht University, Maastricht, The Netherlands; Bernadette M. Jansma, Department of Cognitive Neuroscience, Maastricht University, Maastricht, The Netherlands.

Correspondence concerning this article should be addressed to Loes T. E. Kessels, PO Box 616, 6200 MD Maastricht, the Netherlands. E-mail: lte.kessels@maastrichtuniversity.nl that coffee drinkers were less critical of information questioning the link between caffeine and fibrocystic disease and more critical of information supporting the link than noncoffee drinkers. Similar empirical support for defensive processing of self-relevant threat information has been obtained in recent work on the role of self-affirmation, which demonstrates that defensive reactions can be prevented through strengthening feelings of self-integrity (e.g., Harris et al., 2007; Harris \& Napper, 2005; Sherman, Nelson, \& Steele, 2000; Van Koningsbruggen \& Das, 2009).

\section{Understanding Defensive Reactions}

Theoretically, defensive reactions to threatening health information have been explained primarily with the help of cognitive dissonance theory (Festinger, 1957) and Kunda's (1990) argument for motivated reasoning. That is, individuals experiencing dissonance because their self-image is threatened are motivated to reduce it by changing one of the implicated cognitive or behavioral elements (e.g., perceived risk), for example, through biased processing of compromising information (Liberman \& Chaiken, 1992) or message derogation by refuting message claims (e.g., Brown \& Locker, 2009) and evaluating recommendations as not effective (e.g., Keller, 1999).

In addition, self-report measures of cognitive effort (Liberman \& Chaiken, 1992) and more implicit measures of reading time (Brown \& Locker, 2009) and response time (Klein \& Harris, 2009) have been used to provide an index of the amount of attention that is allocated to threatening health information. These studies suggest that people most at risk react defensively to threatening health information by attending away from the message (or by avoiding the message). However, by definition, these measures do not allow 
a direct observation of the amount of attention that is allocated to the threatening information during message processing. At best, the procedures reflect relatively late information processing stages that feed higher order cognitive processes, such as biased processing, and not the early stage of attention allocation. In the present study, we aimed to explain people's defensive reactions to threatening health messages by studying attention processes during the exposure to high- and low-threat smoking-related pictures among smokers (high self-relevance) and nonsmokers (low selfrelevance).

\section{Attention and Event-Related Potential Analysis}

In the visual attention system, a distinction can be made between attention-capturing and attention-holding processes. Automatic attention capturing is usually driven by salient characteristics of the stimuli (e.g., the valence). The visual attention system also decides whether the stimulus needs to hold attention or whether it is important to shift the attention focus to another place, that is, attention disengagement (Posner, Walker, Friedrich, \& Rafal, 1984). For example, Koster, Crombez, Van Damme, Verschuere, and De Houwer (2004) provided evidence that imminent threat causes attention capturing and attention holding, caused by the phylogenetically old mechanism that directs attention to imminent threat automatically. In the present study, we hypothesized that although threatening health information will automatically cause attention capturing because of its obvious survival value, it will also motivate people to reduce their feeling of dissonance when the information undermines self-relevant goals by disengaging attention from it. People for whom the threat information is selfrelevant will thus be motivated to avoid this information by disengaging from the threat. The latter is, for example, reflected in the use of fewer cognitive resources in detecting visual targets presented in other areas of the visual scene than the threatening cue.

Several paradigms have been used to study attention bias for high-threat stimuli, including the Stroop task, the dot-probe task, the visual search task, or the cueing task (MacLeod, Mathews, \& Tata, 1986; Melara \& Algom, 2003; Posner, 1980; Rabbitt, 1982). In the context of investigating attention allocation processes to health threat information, only one study is known to us that used such an attention paradigm. Klein and Harris (2009) measured attention processes for threatening components of a persuasive message by using a dot-probe task. The study provided evidence that moderately heavy drinkers who were not self-affirmed show an attention bias away from the threat information. However, the setup of the dot-probe task used in that study had the disadvantage of not distinguishing between attention processes such as attention capturing and attention holding (Koster, Crombez, Verschuere, \& De Houwer, 2004). Therefore, Klein and Harris could not conclude what attention processes, less attention capturing or less attention holding, caused the attention bias away from the threat among those participants who were not self-affirmed. In the present study, therefore, we used Posner's (1980) cueing task as it enabled us to measure both attention capturing and attention holding (disengagement) processes to investigate early visual selective attention processes in response to self-relevant health threat information (Koster, Crombez, Van Damme, et al., 2004; Posner, 1980).

In measuring attention allocation processes, we chose to use the high-temporal resolution method of event-related brain potentials
(ERPs). ERPs are derived from a continuous recording of brain activity by means of an electroencephalogram (EEG; for an introduction, see Handy, 2005) and thus enable the assessment of early attention processes during message processing-within milliseconds after stimulus onset. ERP measures provide additional knowledge about different component processes because they do not rely on convergence of effects on a single output measure, such as reaction time or self-report questionnaires (Fichtenholtz, Hopfinger, Graham, Detwiler, \& LaBar, 2007). The relationship between attention allocation, cognitive resources, and ERP is clearly visible in the P300 ERP component (Polich, 2007). The P300 is a relatively late component that is maximal around $300 \mathrm{~ms}$ after stimulus presentation in the central-parietal regions of the brain. The $\mathrm{P} 300$ reflects more controlled attention processes and as such provides an index for cognitive attention allocation and the update of stimulus processing with working memory information (Näätänen, 1992). Because the P300 is dependent on the task requirements of the participant, it reflects the amount of resources necessary for attending (Polich, 2007). ERP studies using Posner's cueing paradigm (Posner, 1980) have reported P300 increases when disengagement was more difficult, reflecting increased resources required to disengage from previously cued stimuli (Correa, Lupiáñez, Madrid, \& Tudela, 2006; Fichtenholtz et al., 2007; Pollak \& Tolley-Schell, 2003).

\section{Overview of the Study and Hypotheses}

In general, the effects of message features and personal characteristics on processes of attention allocation have not been addressed systematically in persuasion research (for an exception, see Ruiter, Kessels, Jansma, \& Brug, 2006; see also Blumberg, 2000; McGuire, 1985). As such, important information about the detailed process of attention allocation as a function of health threat and self-relevance of the persuasive message is missing. In the present study, we sought evidence for the hypothesis that although high-threat information might cause more attention capturing than neutral information because of its evolutionary value (e.g., Koster, Crombez, Van Damme, et al., 2004), people for whom the high-threat information is selfrelevant (i.e., smokers) will be better able to disengage themselves from this negative information than those for whom the negative information is less self-relevant (i.e., nonsmokers). The latter prediction is in line with Kunda's (1990) argument of motivated reasoning and with recent experimental findings (alluded to earlier) that show that people for whom the health message is self-relevant produce an attentional bias away from threatening health information when affirmation resources are missing (Klein \& Harris, 2009) and tend to spend less time reading the high-threat message (Brown \& Locker, 2009).

We investigated the early visual selective attention processes in response to self-relevant health threat information by using Posner's (1980) cueing paradigm. More specifically, we used a variant of Posner's cueing paradigm in which participants reacted to a target (here two horizontal or two vertical dots) presented at the left or right visual field. This target was preceded by a cue (i.e., high- and low-threat smoking pictures) at either the target location (valid trials; $82 \%$ ) or at the opposite location (invalid trials; $18 \%$ ). In this paradigm, valid trials encourage rapid behavioral responses because the presented cue directs the attention immediately to the correct location. In invalid trials, attention must be disengaged from the incorrect location and has to be reallocated toward the 
target position. Reactions to the valid trials thus reflect attentioncapturing processes and reactions to the invalid trials reflect attention-holding (disengagement) processes (Koster, Crombez, Van Damme, et al., 2004; Posner et al., 1984). We tested smokers and nonsmokers to introduce the factor of self-relevance (high vs. low) of the health threat information.

Our main hypotheses focused on the reactions to the targets in the invalid trials, reflecting disengagement processes. We expected that people would react defensively to self-relevant threatening health information by disengaging from it. In other words, smokers would more easily disengage attention from high-threat smoking pictures than would those less affected by the health threat (nonsmokers). Therefore, we hypothesized that smokers would need fewer resources to disengage their attention from the cued location to the invalid target location in the high- as opposed to low-threat conditions. Because the use of fewer attention resources is reflected in lower P300 amplitudes and faster reaction times, we expected lower P300 amplitudes and faster reaction times for the high-threat invalid trials than for the low-threat invalid trials. For nonsmokers, we did not expect these effects because of the absence of defensive responses.

For the reactions to the targets in the valid trials, reflecting attention-capturing processes, we expected the same pattern of results for smokers and nonsmokers. Attention will be directed to imminent threat automatically because of its survival value, resulting in more attention-capturing preferences for high-threat as opposed to low-threat smoking pictures for both smokers and nonsmokers. Because the use of more attention resources is reflected in higher P300 amplitudes and faster reaction times, this general attention bias for high-threat smoking stimuli above neutral stimuli (e.g., Koster, Crombez, Van Damme, et al., 2004) will result in faster reaction times and higher P300 amplitudes for the highthreat than for the low-threat valid trials (cf. Ito, Larsen, Smith, \& Cacioppo, 1998).

\section{Method}

\section{Participants and Experimental Design}

Thirty psychology undergraduate students took part in the experiment, 15 daily smoking ( 7 women) and 15 nonsmoking students (8 women). A self-report measure of smoking behavior (i.e., "How many cigarettes do you smoke a day?") showed that smoking participants smoked on average $6.75(S D=4.93)$ cigarettes a day. Nonsmoking participants reported never having smoked. Smoking and nonsmoking participants were 18 to 25 years of age $(M=21$ years, $S D=1.5$ ), right-handed, and reported having normal or corrected-tonormal vision. Participants were recruited from various public places at the university and took part for course credit. The experiment varied the level of threat of the smoking pictures (low vs. high) and validity of the trials (valid vs. invalid) as within-subjects factors and included smoking status (smoker vs. nonsmoker) as a between-subjects factor. Because the data set of one female smoking participant could not be used because of too many movement artifacts and eye movements, 29 participants remained in the sample and were included in the analyses.

\section{Materials}

Thirty color smoking-related pictures with a high or a low threatening content were used as cues in the cueing task. The high-threat stimuli contained pictures with black lungs, children near smoking cigarettes, skeletons with a smoking cigarette, and other images that illustrate the negative health consequences of smoking. The low-threat pictures showed smoking cigarettes, packages of cigarettes, people smoking cigarettes, and other images that do not directly focus on the negative health consequences of smoking (see Figure 1 for examples). The selection of the 30 smoking pictures was based on a pilot study in which we presented 120 smoking pictures to 16 smoking and 16 nonsmoking undergraduate students. They had to rate on 9-point scales the perceived level of threat $(1=$ not at all, $9=$ very much $)$ and arousal $(1=$ calm, 9 = excited $)$ for each smoking picture. Finally, we made a selection of 15 high-threat smoking pictures with a minimum score of 4.5 on both scales and 15 low-threat smoking pictures with a maximum score of 3 on both scales. The 30 selected pictures were used as stimulus material for the main experiment. The pictures $(11.8 \times 8.5 \mathrm{~cm})$ were presented at the left or right side of the midpoint of a 17-in. computer screen (distance: $8 \mathrm{~cm}$ ). The target stimuli were either two horizontal (. .) or two vertical (:) dots. Throughout the whole experiment, a fixation cross was presented in the middle of the computer screen (see Figure 2 for an outline of the cueing task).
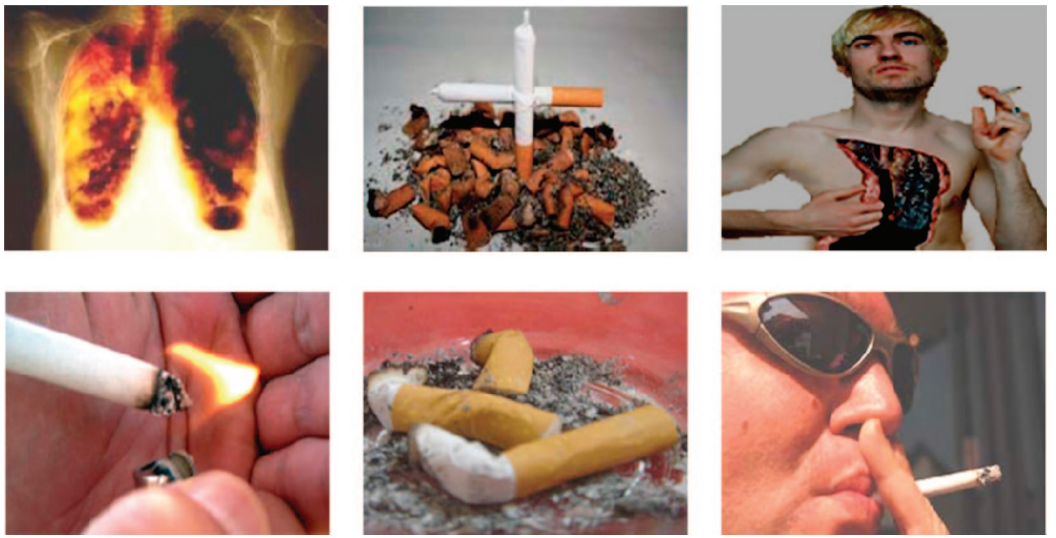

Figure 1. Examples of three high-threat pictures (top row) and three low-threat pictures (bottom row) used as cues. 
Valid Trial

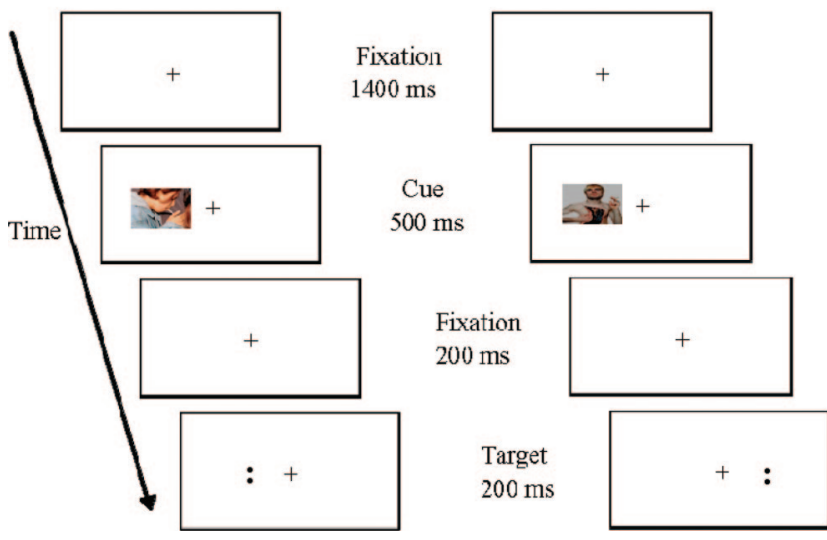

Figure 2. Illustration of the experiment. The valid trial shows an example of the low-threat smoking pictures and the invalid trial shows an example of the high-threat smoking pictures.

\section{Procedure}

The study took place in a dimly lit, sound-attenuating, electrically shielded cabin. After the electrode cap was mounted, the participants sat in a chair approximately $80 \mathrm{~cm}$ from the monitor displaying the stimuli and the experimental task was explained to them. In each trial of the cueing task, a fixation period of $1,400 \mathrm{~ms}$ was followed by a high- or low-threat cue for $500 \mathrm{~ms}$ (see Figure 2). After a second fixation period of $200 \mathrm{~ms}$, a target stimulus was presented for $200 \mathrm{~ms}$, either on the same side of the screen as the cue (valid trial) or on the opposite side of the screen (invalid trial). In the valid condition ( $82 \%$ of trials), the cue correctly indicated the position of the upcoming target. In the invalid condition $(18 \%$ of trials), the cue appeared on the field opposite the subsequent target. The intertrial interval was $2,300 \mathrm{~ms}$. The cue-target combinations were intermingled randomly within each experimental run. Participants were instructed to keep their eyes fixated on the fixation cross and to press as quickly as possible the left button when two horizontal dots were presented as target and to press the right button when two vertical dots were presented.

Before the start of the experiment, participants were told that the probability of a valid trial was larger than the probability of an invalid trial. A practice block of 2 min trained participants to respond correctly to the target while keeping their gaze fixed on the fixation cross. The experimental session consisted of 1,320 trials (cue and target), with 1,080 valid trials and 240 invalid trials. Within the valid and invalid trials, type and presentation side of the two targets (horizontal and vertical dots) were counterbalanced. Following the cueing task, participants evaluated each smoking picture on the perceived level of threat $(1=$ not at all, $9=$ very much $)$ and arousal $(1=$ calm, $9=$ excited). The whole experiment lasted about $2 \mathrm{hr}$, including the mounting and removal of the electrode cap.

\section{Measures}

Reaction times and errors. Button-press responses were measured from target onset. Errors consisted of mistakes (pressed right for horizontal dots and pressed left for vertical dots), misses (no button press), and reactions faster than $120 \mathrm{~ms}$.
EEG and ERPs. The EEG was recorded from 30 scalp sites (an extended version of the 10/20 system) with tin electrodes mounted in an electrode cap, with the electrodes referenced online to the left mastoid signal. A bipolar montage, with electrodes placed on the right and left external canthus, recorded horizontal eye movements. Vertical eye movements and eyeblinks were measured by a bipolar montage of electrodes placed on the upper and lower orbital ridge of the left eye. The electro-oculogram was recorded for later offline rejection of trials contaminated with eye movements. All electrode impedances (EEG and electrooculogram) were kept below $5 \mathrm{k} \Omega$.

EEG and electro-oculogram signals were digitized at a $250-\mathrm{Hz}$ sampling rate and amplified by using a 32-channel NeuroScan SynAmps amplifier. The continuous EEG was filtered offline with a bandpass filter of 0.05 to $30 \mathrm{~Hz}$. For ERP analysis, epochs of 1,500 $\mathrm{ms}$ were obtained from the continuous EEG signal, starting $100 \mathrm{~ms}$ before onset of the cue and ending $700 \mathrm{~ms}$ after target offset. The 100-ms precue interval was used as a baseline. Epochs containing artifacts, including eye movements, beyond -100 and $100 \mu \mathrm{V}$ were removed before analysis; the overall rejection rate of the analyzed trials was $21 \%$. Finally, ERPs were derived by averaging for each participant the EEG sequences for each combination of threat, validity, and electrode site. Subsequently, a grand average of these individual ERP data for each experimental condition and electrode site was calculated per smoking status group.

\section{Analyses}

Reaction times and errors were subjected to mixed analyses of variance (ANOVAs) with threat (high vs. low) and validity (valid vs. invalid trials) as the within-subjects factors and smoking status (smoker vs. nonsmoker) as the between-subjects factor. ERP analyses were restricted to the midline electrodes $\mathrm{Fz}, \mathrm{FCz}, \mathrm{Cz}, \mathrm{CPz}$, and $\mathrm{Pz}$ because the peak amplitudes were largest for these midline electrodes and the expected attention effects are generally largest for the midline electrodes (Johnson, 1993; Polich, 2007). Because of the unequal distribution of the number of valid and invalid trials, different ERP response patterns on reactions to the target stimuli were expected as a function of validity. Therefore separate mixed ANOVAs were performed for the reactions on the valid and the invalid targets with threat (high vs. low) and electrodes (5) as the within-subjects factors and smoking status (smokers vs. nonsmokers) as the between-subjects factor. Significant interactions were followed by simple effect analyses. To control for sphericity violations in the mixed ANOVAs, we report probability values with Greenhouse-Geisser correction for $F$ tests with more than 1 degree of freedom in the numerator. The reported estimates of the effect size are partial eta squared $\left(\eta_{\mathrm{p}}^{2}\right)$ for the ANOVAs and Cohen's $d$ for the paired samples $t$ tests.

\section{Results}

\section{Error Analysis}

Mean percentages of errors, omissions, premature responses (reactions faster than $120 \mathrm{~ms}$ ), and trials with EEG artifacts that were removed from the data are presented in Table 1. For the number of errors on the target detection task, a significant interaction between validity and smoking status was found, $F(1,27)=$ 
Table 1

Behavioral Performance Measures as a Function of Trial Validity, Threat, and Smoking Status

\begin{tabular}{|c|c|c|c|c|c|c|c|c|}
\hline \multirow[b]{3}{*}{ Variable } & \multicolumn{4}{|c|}{ Valid } & \multicolumn{4}{|c|}{ Invalid } \\
\hline & \multicolumn{2}{|c|}{ High } & \multicolumn{2}{|c|}{ Low } & \multicolumn{2}{|c|}{ High } & \multicolumn{2}{|c|}{ Low } \\
\hline & $M$ & $S D$ & $M$ & $S D$ & $M$ & $S D$ & $M$ & $S D$ \\
\hline \multicolumn{9}{|c|}{ Reaction time (ms) } \\
\hline Smokers & 470 & 46 & 471 & 47 & 498 & 52 & 493 & 49 \\
\hline Nonsmokers & 488 & 56 & 490 & 59 & 514 & 59 & 513 & 55 \\
\hline \multicolumn{9}{|l|}{ Omission } \\
\hline Smokers & 6.84 & 12.13 & 7.00 & 12.79 & 7.62 & 12.88 & 7.44 & 12.67 \\
\hline Nonsmokers & 4.52 & 8.01 & 4.41 & 7.66 & 5.11 & 8.09 & 4.72 & 7.58 \\
\hline \multicolumn{9}{|l|}{ Premature } \\
\hline Smokers & 0.04 & 0.15 & 0.03 & 0.10 & 0.00 & 0.00 & 0.00 & 0.00 \\
\hline Nonsmokers & 0.01 & 0.05 & 0.00 & 0.00 & 0.00 & 0.00 & 0.06 & 0.22 \\
\hline \multicolumn{9}{|l|}{ Error } \\
\hline Smokers & 1.93 & 1.31 & 1.88 & 1.31 & 3.45 & 2.63 & 2.86 & 2.83 \\
\hline Nonsmokers & 2.33 & 1.86 & 2.27 & 1.67 & 2.67 & 2.46 & 1.94 & 1.77 \\
\hline \multicolumn{9}{|l|}{ EEG artifact } \\
\hline Smokers & 8.49 & 9.08 & 11.22 & 12.05 & 6.67 & 7.74 & 8.10 & 9.84 \\
\hline Nonsmokers & 10.63 & 9.75 & 13.48 & 13.19 & 9.94 & 8.79 & 11.33 & 10.22 \\
\hline \multicolumn{9}{|l|}{ Total reject } \\
\hline Smokers & 17.30 & 11.96 & 20.12 & 16.66 & 17.74 & 11.82 & 18.39 & 13.17 \\
\hline Nonsmokers & 17.49 & 11.07 & 20.16 & 14.56 & 17.72 & 10.18 & 18.06 & 11.96 \\
\hline
\end{tabular}

Note. Unless otherwise indicated, all values are percentages.

5.03, $p<.05, \eta_{\mathrm{p}}^{2}=.16$. A paired samples $t$ test showed that smokers made more errors on invalid trials than on valid trials, $t(13)=2.90, p<.05, d=0.65$. For nonsmokers, no difference in the number of errors was detected between the invalid and valid trials, $t(14)=0.01, p=.99, d=0.01$. No further main effects or interactions involving threat or smoking status were found for the proportion of EEG artifacts, the number of omissions, and premature responses, $F \mathrm{~s}<3.04, n s, \eta_{\mathrm{p}}^{2}<.10$. For the final analyses, we used $79 \%$ of the original data.

\section{Reaction Times}

Table 1 presents mean reaction times to the target stimuli (horizontal and vertical dots). The mixed ANOVA revealed a significant main effect of validity, $F(1,27)=141.90, p<.001$, $\eta_{\mathrm{p}}^{2}=.84$. As expected, reaction times to the targets were faster for the valid targets than for the invalid targets. No further main effects or interactions involving threat and smoking status were found, $F \mathrm{~s}<2.59, n s, \eta_{\mathrm{p}}^{2}<.09$.

\section{ERP Analyses}

Visual inspection. Visual inspection of the ERP waves on reaction to the target stimuli shows the expected P300 effect between approximately 360 and $560 \mathrm{~ms}$ after target presentation (see Figures 3 and 4). For the invalid trials, smokers provided lower peak amplitudes for the high-threat trials than for the low-threat trials (see Figure 3). For nonsmokers, no difference in peak amplitudes on reaction to the invalid trials is visible (see Figure 3). Reactions to the valid trials show for both groups higher peak amplitudes for the high-threat trials than for the low-threat trials (see Figure 4).

P300. Mixed ANOVAs for the invalid trials revealed a significant interaction between threat and smoking status, $F(1,27)=$
$4.80, p<.05, \eta_{\mathrm{p}}^{2}=.15$, and a significant main effect of electrodes, $F(4,108)=52.92, p<.001, \eta_{\mathrm{p}}^{2}=.66$. Separate analyses for each level of smoking status showed for smokers the expected pattern, with lower P300 amplitudes for the high-threat than for the lowthreat trials, $F(1,13)=16.22, p<.01, \eta_{\mathrm{p}}^{2}=.55$. Although all electrodes showed lower P300 amplitudes for the high- as opposed to the low-threat trials (see Table 2), the topographical map of the signal distribution indicates that the expected P300 effect was most strongly concentrated at the central-parietal electrodes (see Figure $3)$. For nonsmokers, only a main effect of electrodes was found, $F(4,56)=34.27, p<.001, \eta_{\mathrm{p}}^{2}=.71$.

For the valid trials, the mixed ANOVA revealed a significant main effect of threat, $F(1,27)=21.32, p<.001, \eta_{\mathrm{p}}^{2}=.44$, and a main effect of electrodes, $F(4,108)=54.12, p<.001, \eta_{\mathrm{p}}^{2}=.67$. Higher P300 amplitudes were found for the high- as opposed to the low-threat trials across electrode sites and smoking status (see Table 2). The topographical map of the signal distribution showed a central-parietal distribution of the P300 effect in reaction to the valid trials (see Figure 4). ${ }^{1}$

\footnotetext{
${ }^{1}$ Because our hypotheses were focused on processes of attention holding and attention disengagement, we restricted the analyses to the responses on the targets in both valid and invalid trials. Visual inspection of the ERP waves in Figures 3 and 4, however, clearly shows a late negativity component, peaking between 280 and $500 \mathrm{~ms}$ after cue presentation, with more negative amplitudes for the high-threat trials than for the low-threat trials. Subsequent analyses confirmed this main effect of threat, $F(1,27)=42.14, p<.001, \eta_{\mathrm{p}}^{2}=.61$, which was not further qualified by validity of the trials or smoking status of the participants $\left(p s>.12, \eta_{\mathrm{p}}^{2}<.09\right)$.
} 


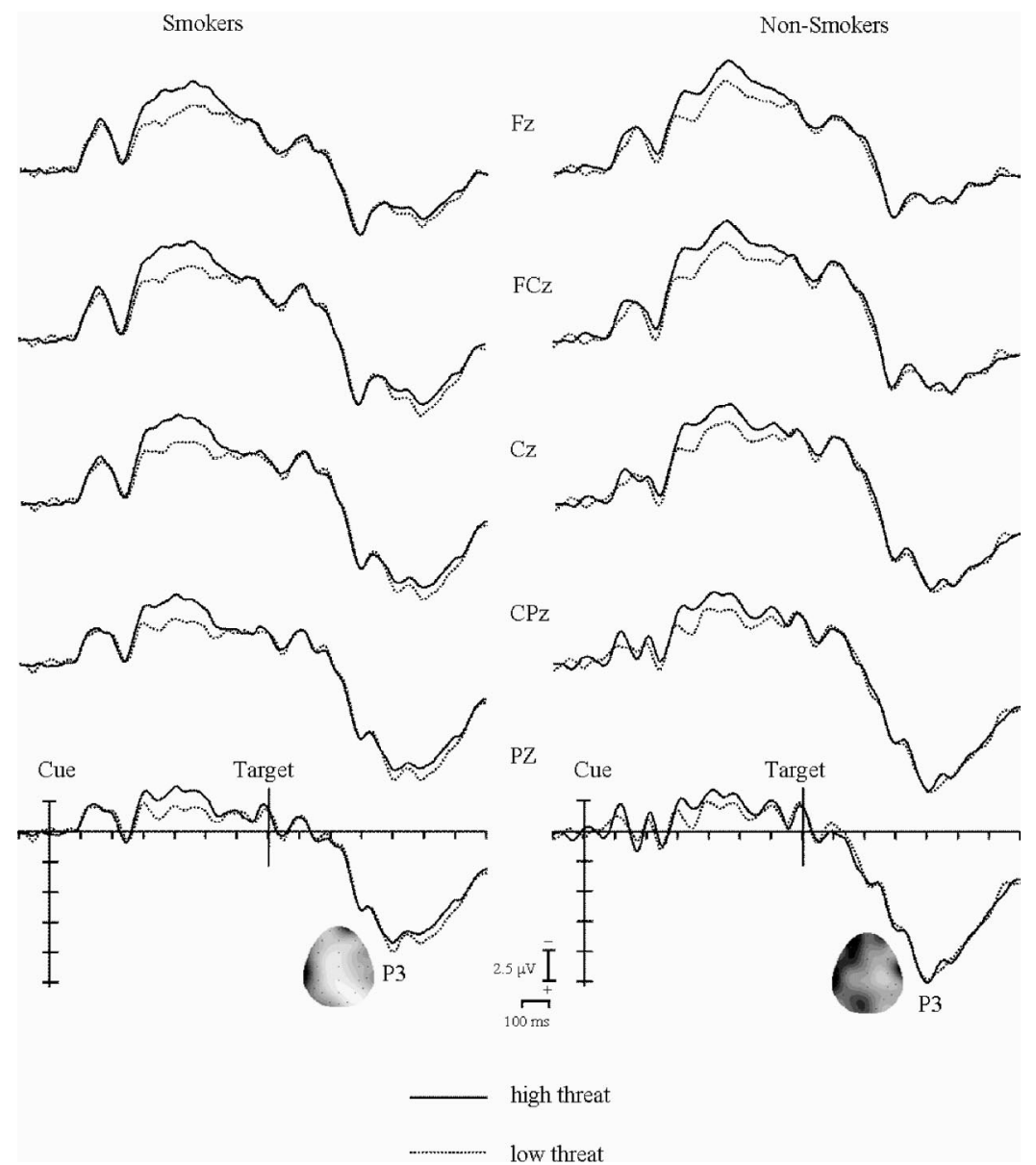

Figure 3. Grand average event-related potential (ERP) waveforms by condition and group for the invalid trials. Scalp distribution maps present the signal distribution for the P300 component. For the P300 component, topographical maps were computed by subtracting the low- from high-threat condition for the invalid trials at $392 \mathrm{~ms}$ after target presentation with a maximum of $1 \mu \mathrm{V}$ (dark gray) and a minimum of $-1 \mu \mathrm{V}$ (white). Electrode locations are marked by blocks.

\section{Self-Report Measures}

Mixed ANOVAs showed that, independent of smoking status, the high-threat pictures were judged as being more "threatening" and more "arousing" than the low-threat pictures, $F(1,27)=$ 91.90, $p<.001, \eta_{\mathrm{p}}^{2}=.77$, and $F(1,27)=102.85, p<.001$, $\eta_{\mathrm{p}}^{2}=.79$, respectively (see Table 3 for the mean scores).

\section{Discussion}

In an adapted visual selective attention paradigm investigating the early stage of information processing, we found neuroscientific support for our hypothesis that threatening health information causes more efficient attention disengagement (less attention holding) among those for whom the health threat is self-relevant. As predicted, smokers (but not nonsmokers) showed a decreased P300 amplitude in response to high- as opposed to low-threat smoking stimuli on invalid trials, indicating the use of fewer attentional resources when disengaging attention from the previously cued (threatening) location. The expectation that this finding would also result in faster reaction times for the high-threat compared with the low-threat invalid trials was not supported.

For nonsmokers, no difference in P300 activity was found in reaction to the high-versus low-threat invalid trials. This finding indicates that nonsmokers, for whom the information was supposed to be less self-relevant, have no attention-holding (attention disengagement) preferences for high- versus low-threat smoking pictures.

Besides our specific attention disengagement hypothesis, we predicted, on the basis of the attention preference mechanism for imminent threat, more attention capturing for high- as opposed to low-threat pictures for both smokers and nonsmokers (Koster, Crombez, Van Damme, et al., 2004). Support for our hypothesis was observed in the parietal distributed P300 amplitudes in reaction to the valid targets, with higher amplitudes for the high-threat than for the low-threat trials. This finding indicates that both smokers and nonsmokers used increased resources to capture attention for high-threat smoking information irrespective of whether or not the information was self-relevant. Again, the reaction time data did not mirror these ERP data. 


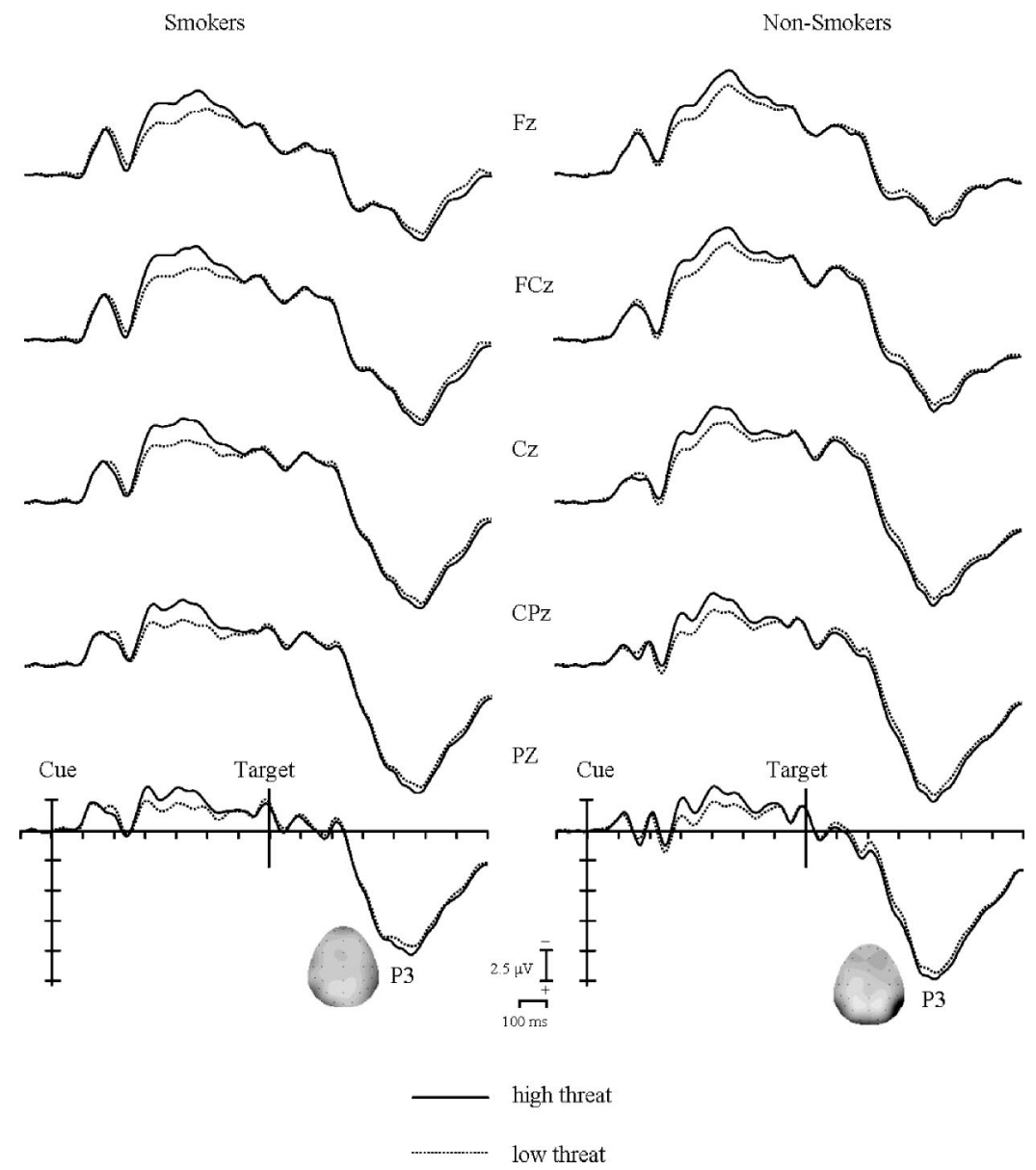

Figure 4. Grand average event-related potential (ERP) waveforms by condition and group for the valid trials. Scalp distribution maps present the signal distribution for the P300 component. For the P300 component, maps were computed by subtracting high from low threat condition for the valid trials at $384 \mathrm{~ms}$ after target presentation with a maximum of $1 \mu \mathrm{V}$ (dark gray) and a minimum of $-1 \mu \mathrm{V}$ (white). Electrode locations are marked by blocks.

Our ERP findings for the smoking participants are in line with the view that people are motivated to reduce feelings of cognitive dissonance (Festinger, 1957; Kunda, 1990). Whereas previous studies used self-report measures or implicit measures of reading time and response time, the present study provided evidence for motivated reasoning through the use of attention measures during message processing (Brown \& Locker, 2009; Klein \& Harris, 2009). The ERP findings showed that smokers disengaged more efficiently from high-threat as opposed to low-threat health information, implying that people whose self-image was threatened tried to avoid the high-threat information. The ERP findings thus indicate that avoidance responses can arise during the early process of attention allocation.

Following a previous study by Pollak and Tolley-Schell (2003), we used an affective component in a spatial cueing task. On behavioral measures, the more standard variants of the cueing task normally show reaction time benefits and higher accuracy rates for valid over invalid trials (Pollak \& Tolley-Schell). The present study partially supported these findings, with faster reaction times for valid instead of invalid trials for both smoking status groups and a higher accuracy rate in response to valid instead of invalid trials for the group of smokers. Besides this typical validity effect, however, there were no further differences between experimental conditions in reaction times. This suggests that at the end of the cognitive process (during motor preparation), any influence of the combined effect of threat level and message relevance on information processing was cancelled. In contrast, the ERP waves show a fine-grained difference in time windows earlier than response preparation. Indeed, the combination of ERP and reaction time findings in the present study suggests that attention is modulated by message relevance and threat level rather early on in the cognitive processing of health information.

Furthermore, the observation that the reaction time measures did not support the interaction between the level of threat and smoking status observed in the ERP data for the invalid trials indicates that the ERP measure can be extremely informative. The method of ERP in future health communication research can be a useful tool to measure low-level attention biases that are nonetheless relevant in health communication.

A limitation of the present study is that we did not include a no-cue condition whereby the target stimuli were presented without any previous warning, which could have served as a reference 
Table 2

Amplitudes $(\mu V)$ of the P300 Effect as a Function of Trial Validity, Threat, and Smoking Status

\begin{tabular}{|c|c|c|c|c|c|c|c|c|}
\hline \multirow[b]{3}{*}{ Electrode } & \multicolumn{4}{|c|}{ Valid } & \multicolumn{4}{|c|}{ Invalid } \\
\hline & \multicolumn{2}{|c|}{ High } & \multicolumn{2}{|c|}{ Low } & \multicolumn{2}{|c|}{ High } & \multicolumn{2}{|c|}{ Low } \\
\hline & $M$ & $S D$ & $M$ & $S D$ & $M$ & $S D$ & $M$ & $S D$ \\
\hline \multicolumn{9}{|l|}{$\mathrm{Fz}$} \\
\hline Smokers & 6.33 & 4.47 & 5.74 & 4.47 & 5.33 & 4.13 & 6.13 & 4.50 \\
\hline Nonsmokers & 5.36 & 3.62 & 4.65 & 3.51 & 5.22 & 4.62 & 5.47 & 4.40 \\
\hline \multicolumn{9}{|l|}{$\mathrm{FCz}$} \\
\hline Smokers & 8.15 & 5.26 & 7.57 & 5.51 & 6.44 & 4.91 & 7.57 & 5.28 \\
\hline Nonsmokers & 7.08 & 4.86 & 6.38 & 4.90 & 6.73 & 5.49 & 6.81 & 5.61 \\
\hline \multicolumn{9}{|l|}{$\mathrm{Cz}$} \\
\hline Smokers & 9.95 & 5.18 & 9.43 & 5.43 & 8.53 & 5.28 & 9.53 & 5.49 \\
\hline Nonsmokers & 9.61 & 5.48 & 8.95 & 5.62 & 8.91 & 5.59 & 9.09 & 5.89 \\
\hline \multicolumn{9}{|l|}{$\mathrm{CPz}$} \\
\hline Smokers & 11.78 & 4.61 & 11.30 & 4.75 & 9.96 & 4.65 & 11.42 & 4.78 \\
\hline Nonsmokers & 12.42 & 5.62 & 11.73 & 5.72 & 11.67 & 5.54 & 12.01 & 5.68 \\
\hline \multicolumn{9}{|l|}{$\mathrm{Pz}$} \\
\hline Smokers & 11.44 & 3.84 & 10.90 & 3.56 & 9.99 & 3.82 & 11.14 & 3.66 \\
\hline Nonsmokers & 13.29 & 5.55 & 12.75 & 5.60 & 13.34 & 5.80 & 13.34 & 5.51 \\
\hline
\end{tabular}

point to investigate the "validity effect" on the reaction times (Perchet \& García-Larrea, 2000; Posner, Inhoff, Friedrich, \& Cohen, 1987; Posner et al., 1984; Swanson et al., 1991). Using a no-cue condition is common in behavioral studies using the cueing task, but it is less often used when ERP measures are added as a dependent measure because those trials may introduce another confound, namely that of surprise or unanticipated stimuli (Jonides \& Mack, 1984; Pollak \& Tolley-Schell, 2003). Because we did not include no-cue trials, we could not conclude whether the validity effect we found was attributable to a cost associated with an invalid cue or a benefit associated with a valid cue.

The present findings indicate that whether high-threat health information attracts and holds attention is dependent on whether the information is self-relevant. In line with previous research, indicating that high-threat health information causes denial as a coping strategy (Brown \& Locker, 2009), the use of high-threat information may be counterproductive for people performing the risky behavior. As previous studies have proposed, message recipients could be prepared for potentially distressing messages by using prior affirmative experiences (Brown \& Locker, 2009; Harris et al., 2007). Although self-affirmation techniques can enhance

Table 3

Scores on Perceived Threat and Arousal Scales as a Function of Threat

\begin{tabular}{llllll}
\hline & \multicolumn{5}{c}{ Threat } \\
\cline { 2 - 5 } & \multicolumn{2}{c}{ High } & & \multicolumn{2}{c}{ Low } \\
\cline { 2 - 3 } \cline { 5 - 6 } Variable & $M$ & $S D$ & & $M$ & $S D$ \\
\hline Threat & & & & \\
$\quad$ Smokers & 5.13 & 1.22 & 2.40 & 1.39 \\
$\quad$ Nonsmokers & 4.73 & 2.03 & 2.22 & 0.84 \\
Arousal & & & & \\
$\quad$ Smokers & 5.51 & 1.28 & 2.60 & 1.17 \\
$\quad$ Nonsmokers & 5.31 & 1.69 & 2.80 & 1.29 \\
\hline
\end{tabular}

attention biases toward threat information (Klein \& Harris, 2009), future studies should explore with online attention measures whether the use of self-affirmation techniques prior to message exposure diminishes attention disengagement processes, for example, by using the attention cueing task.

In conclusion, the present study, in which we used a wellvalidated spatial cueing task, showed that high-threat smoking pictures capture more attention processes than low-threat smoking pictures both in smokers and nonsmokers. At the same time, high-threat smoking pictures caused more efficient disengagement processes than low-threat smoking pictures, but only in smokers. Neuroscientific support was thus found for previous self-report findings that showed that self-relevant health information leads to more defensive reactions when the message contains high-instead of low-threat information.

\section{References}

Blumberg, S. J. (2000). Guarding against threatening HIV prevention messages: An information-processing model. Health Education \& Behavior, 27, 780-795.

Brown, S., \& Locker, E. (2009). Defensive responses to an emotive anti-alcohol message. Psychology \& Health, 24, 517-528.

Correa, Á., Lupiáñez, J., Madrid, E., \& Tudela, P. (2006). Temporal attention enhances early visual processing: A review and new evidence from event-related potentials. Brain Research, 1076, 116-128.

Croyle, R. T., Sun, Y. C., \& Hart, M. (1997). Processing risk factor information: Defensive biases in health-related judgments and memory. In K. J. Petrie \& J. Weinman (Eds.), Perceptions of health and illness: Current research and applications (pp. 267-290). Amsterdam: Harwood Academic.

Ditto, P. H., \& Croyle, R. T. (2003). Understanding the impact of risk factor test results: Insights from a basic research program. In P. Salovey \& A. J. Rothman (Eds.), Social psychology of health (pp. 98-117). New York: Psychology Press.

Festinger, L. (1957). A theory of cognitive dissonance. Oxford, England: Stanford University Press.

Fichtenholtz, H. M., Hopfinger, J. B., Graham, R., Detwiler, J. M., \& LaBar, K. S. (2007). Happy and fearful emotion in cues and targets 
modulate event-related potential indices of gaze-directed attentional orienting. Social Cognitive and Affective Neuroscience, 2, 323-333.

Fishbein, M., Triandis, H. C., Kanfer, F. H., Becker, M., \& Middlestadt, S. E. (2000). Factors influencing behavior and behavior change. In A. S. Baum, T. A. Revenson, \& J. E. Singer (Eds.), Handbook of health psychology (pp. 1-17). Mahwah, NJ: Erlbaum.

Freeman, M. A., Hennessy, E. V., \& Marzullo, D. M. (2001). Defensive evaluation of antismoking messages among college-age smokers: The role of possible selves. Health Psychology, 20, 424-433.

Handy, T. C. (Ed.). (2005). Event-related potentials: A methods handbook. Cambridge, MA: MIT Press.

Harris, P. R., Mayle, K., Mabbott, L., \& Napper, L. (2007). Selfaffirmation reduces smokers' defensiveness to graphic on-pack cigarette warning labels. Health Psychology, 26, 437-446.

Harris, P. R., \& Napper, L. (2005). Self-affirmation and the biased processing of threatening health-risk information. Personality and Social Psychology Bulletin, 31, 1250-1263.

Ito, T. A., Larsen, J. T., Smith, N. K., \& Cacioppo, J. T. (1998). Negative information weighs more heavily on the brain: The negativity bias in evaluative categorizations. Journal of Personality and Social Psychology, 75, 887-900.

Johnson, R. (1993). On the neural generators of the P300 component of the event-related potential. Psychophysiology, 30, 90-97.

Jonides, J., \& Mack, R. (1984). On the cost and benefit of cost and benefit. Psychological Bulletin, 96, 29-44.

Keller, P. A. (1999). Converting the unconverted: The effect of inclination and opportunity to discount health-related fear appeals. Journal of Applied Psychology, 84, 403-415.

Keller, P. A., \& Block, L. G. (1999). The effect of affect-based dissonance versus cognition-based dissonance on motivated reasoning and healthrelated persuasion. Journal of Experimental Psychology: Applied, 5, 302-313.

Klein, W. M. P., \& Harris, P. R. (2009). Self-affirmation enhances attentional bias toward threatening components of a persuasive message. Psychological Science, 20, 1463-1467.

Koster, E. H. W., Crombez, G., Van Damme, S., Verschuere, B., \& De Houwer, J. (2004). Does imminent threat capture and hold attention? Emotion, 4, 312-317.

Koster, E. H. W., Crombez, G., Verschuere, B., \& De Houwer, J. (2004). Selective attention to threat in the dot probe paradigm: Differentiating vigilance and difficulty to disengage. Behavior Research and Therapy, 42, 1183-1192.

Kunda, Z. (1990). The case for motivated reasoning. Psychological Bulletin, 108, 480-498.

Leventhal, H. (1970). Findings and theory in the study of fear communication. In L. Berkowitz (Ed.), Advances in experimental social psychology (Vol. 5, pp. 119-186). San Diego, CA: Academic Press.

Liberman, A., \& Chaiken, S. (1992). Defensive processing of personally relevant health messages. Personality and Social Psychology Bulletin, 18, 669-679.

MacLeod, C., Mathews, A., \& Tata, P. (1986). Attentional bias in emotional disorders. Journal of Abnormal Psychology, 95, 15-20.
Maddux, J. E., \& Rogers, R. W. (1983). Protection motivation and selfefficacy: A revised theory of fear appeals and attitude change. Journal of Experimental Social Psychology, 19, 469-479.

McGuire, W. J. (1985). Attitude and attitude change. In G. Lindzey \& E. Aronson (Eds.), The handbook of social psychology (pp. 233-346). New York: Random House.

Melara, R. D., \& Algom, D. (2003). Driven by information: A tectonic theory of Stroop effects. Psychological Review, 110, 422-471.

Näätänen, R. (1992). Attention and brain function. Hillsdale, NJ: Erlbaum.

Perchet, C., \& García-Larrea, L. (2000). Visuospatial attention and motor reaction in children: An electrophysiological study of the "Posner" paradigm. Psychophysiology, 37, 231-241.

Polich, J. (2007). Updating P300: An integrative theory of P3a and P3b. Clinical Neurophysiology, 118, 2128-2148.

Pollak, S. D., \& Tolley-Schell, S. A. (2003). Selective attention to facial emotion in physically abused children. Journal of Abnormal Psychology, 112, 323-338.

Posner, M. I. (1980). Orienting of attention. Quarterly Journal of Experimental Psychology, 32, 3-25.

Posner, M. I., Inhoff, A. W., Friedrich, F. J., \& Cohen, A. (1987). Isolating attentional systems: A cognitive-anatomical analysis. Psychobiology, $15,107-121$.

Posner, M. I., Walker, J. A., Friedrich, F. J., \& Rafal, R. D. (1984). Effects of parietal injury on covert orienting of attention. The Journal of Neuroscience, 4, 1863-1874.

Rabbitt, P. (1982). Visual search. In C. R. Puff (Ed.), Handbook of research methods in human memory and cognition (pp. 27-62). New York: Academic Press

Ruiter, R. A. C., Kessels, L. T. E., Jansma, B. M., \& Brug, J. (2006). Increased attention for computer-tailored health communications: An event-related potential study. Health Psychology, 25, 300-306.

Ruiter, R. A. C., \& Kok, G. (2005). Saying is not (always) doing: Cigarette warning labels are useless. European Journal of Public Health, 15, 329-330.

Ruiter, R. A. C., \& Kok, G. (2006). Response to Hammond et al. showing leads to doing, but doing what? The need for experimental pre-testing. European Journal of Public Health, 16, 225.

Sherman, D. A. K., Nelson, L. D., \& Steele, C. M. (2000). Do messages about health risks threaten the self? Increasing the acceptance of threatening health messages via self-affirmation. Personality and Social Psychology Bulletin, 26, 1046-1058.

Swanson, J. M., Posner, M. I., Potkin, S. G., Bonforte, S., Youpa, D., Fiore, C., . . . Crinella, F. (1991). Activating tasks for the study of visual-spatial attention in ADHD children: A cognitive anatomic approach. Journal of Child Neurology, 6, 119-127.

Van Koningsbruggen, G. M., \& Das, E. (2009). Don't derogate this message! Self-affirmation promotes online type 2 diabetes risk test taking. Psychology \& Health, 24, 635-649.

Witte, K. (1992). Putting the fear back into fear appeals: The extended parallel process model. Communication Monographs, 59, 329-349. 